\title{
The Achilles heel of composite arterial grafting: Early occlusion of the distal right coronary limb
}

Elliot J. Smith, MRCP, ${ }^{a}$ Ragheb Hasan, ChM, FRCS, ${ }^{\text {b }}$ and

Nicholas P. Curzen, PhD, MRCP, ${ }^{a}$ Manchester, United Kingdom

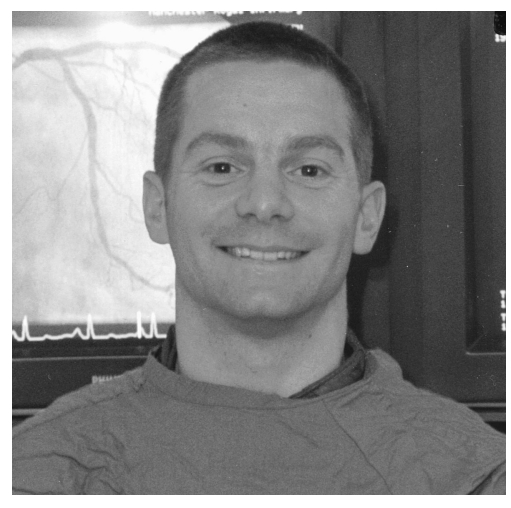

Dr Curzen

$\mathrm{O}$ ff-pump bypass grafting (OPCAB) for coronary artery disease is recognized as a safe alternative to conventional surgery, with comparable graft patency rates. ${ }^{1}$ "Composite" arterial conduits are increasingly being used to allow complete arterial revascularization. These usually comprise the left internal thoracic artery (LITA) to the left anterior descending coronary artery (LAD) territory, with the right internal thoracic (RITA), radial artery, or gastroepiploic artery fashioned as a $\mathrm{T}$ or $\mathrm{Y}$ graft to the other coronaries. Although there are data to suggest good composite patency at 1 year, this is exclusively in the context of conventional cardiopulmonary bypass. ${ }^{2}$ Patency data for OPCAB composite grafts are sparse. ${ }^{3}$

We present 3 cases in which early loss of the distal limb of a composite graft to the posterior descending artery (PDA) caused recurrent symptoms after initially successful OPCAB. This was successfully treated with percutaneous intervention to the native right coronary artery (RCA) in 2 cases.

\section{Clinical Summaries}

CASE 1. A 47-year-old Asian man was seen with angina and a positive exercise tolerance test result. Coronary angiography revealed 3-vessel disease with preserved left ventricular function. The RCA had a severe stenosis proximal to the bifurcation, and the left ventricular branch of the RCA was occluded proximally (Figure $1, B$ and $C$ ). The patient underwent off-pump total arterial revascularization (5 vessels). A composite graft was fashioned with the LITA anastomosed to the LAD and diagonal branch sequentially, and the RITA anastomosed end to side to the LITA

From the Departments of Cardiology ${ }^{\mathrm{a}}$ and Cardiac Surgery, ${ }^{\mathrm{b}}$ Manchester Heart Centre, Manchester Royal Infirmary, Manchester, United Kingdom.

Received for publication Dec 20, 2001; accepted for publication Jan 4, 2002

Address for reprints: Nicholas P. Curzen, PhD, MRCP, Consultant Cardiologist, Manchester Heart Centre, Manchester M13 9WL, United Kingdom (E-mail: nc@mhc.cmht.nwest.nhs.uk).

J Thorac Cardiovasc Surg 2002;124:186-8

Copyright @ 2002 by The American Association for Thoracic Surgery

$0022-5223 / 2002 \$ 35.00+0 \quad \mathbf{1 2 / 5 4 / 1 2 2 6 8 2}$

doi: $10.1067 / \mathrm{mtc} .2002 .122682$ and then sequentially to the intermediate, left ventricular, and PDA branches of the RCA.

After an uncomplicated recovery, the patient was seen 12 weeks later with angina and new electrocardiographic changes. Repeated angiography showed patency of all graft elements except the final limb to the PDA, which had residual antegrade flow (Figure 1, $A$ and $B$ ). Through a 6F Judkins Right guiding catheter the lesion was crossed with a 0.014 -inch floppy wire and predilated with a $3.0 \times 20$-mm monorail balloon. A $4.0 \times 18-\mathrm{mm}$ Multi-link Tetra stent (Guidant Ltd, Hanks, United Kingdom) was deployed to high pressure across the bifurcation (Figure 1, $C$ ).

CASE 2. A 53-year-old man with a previous inferior myocardial infarction was seen with limiting angina. Angiography revealed significant 3-vessel coronary disease with moderate left ventricular function. The RCA was a large-caliber vessel with a significant $(60 \%)$ stenosis proximally but brisk antegrade flow. The patient underwent 3-vessel OPCAB with a composite graft comprising the LITA to the LAD and the RITA sequentially to the obtuse marginal branch of the circumflex coronary artery (OM) and the PDA.

After 3 months, the patient's angina returned. Repeated catheterization showed patency of the LAD and OM limbs but occlusion of the distal graft to the PDA, which had retained antegrade flow. With an AR2 6F guide catheter the lesion was crossed with a 0.014-inch extra support wire and stented directly using a $4.0 \times$ 13-mm BX Velocity stent (Cordis Corp, Miami, Fla).

CASE 3. A 46-year-old woman with diabetes was seen with angina and a positive exercise tolerance test result. Cardiac catheterization confirmed 3-vessel disease with good left ventricular function. Her RCA was diffusely diseased, with TIMI III flow. She underwent 3-vessel OPCAB with a composite LITA to the LAD, and the RITA sequentially to the second OM and the PDA.

Angina returned after 3 months. Angiography showed a widely patent graft of the LITA and RITA to the OM, but the distal PDA limb was occluded. Currently this patient is being treated medically, but percutaneous intervention remains an option.

\section{Discussion}

We present here 3 cases of composite arterial coronary grafts performed with the OPCAB technique, all with the distal limb occluding early. In all cases this limb was anastomosed to a distal native RCA, which itself retained brisk antegrade flow. In the case of saphenous vein grafts, early occlusion usually results from 

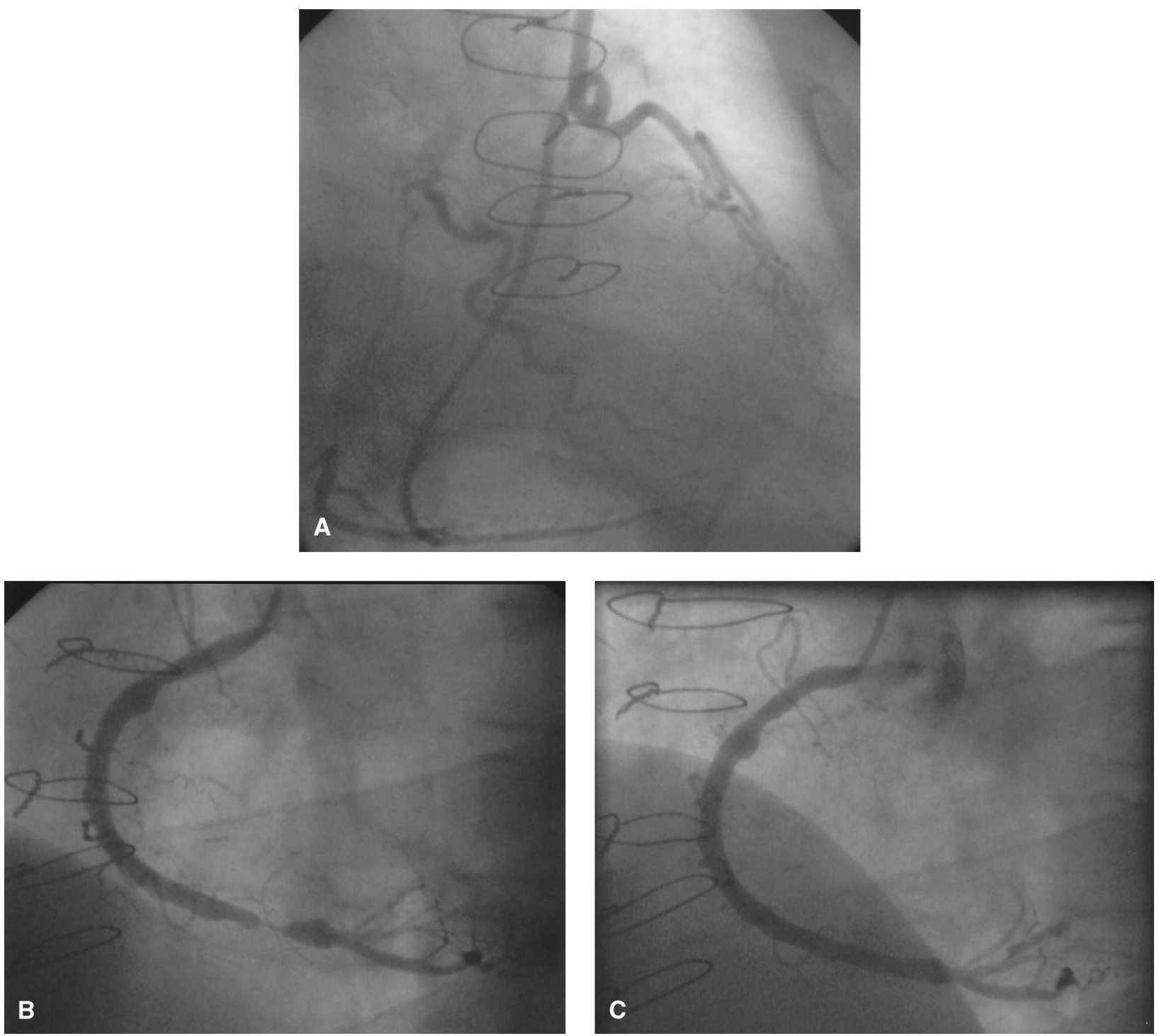

Figure 1. (A) Right anterior oblique projection of composite graft to LAD and diagonal, intermediate, and left ventricular branches of RCA. (B) Left anterior oblique projection of native RCA showing large ungrafted PDA. Note that left ventricular branch of RCA is occluded after bifurcation but has patent graft (above). (C) Left anterior oblique projection of native RCA after percutaneous intervention.

thrombosis. Thereafter atherosclerosis predominates, with a background of neointimal proliferation. As many as $12 \%$ of vein grafts occlude before discharge, and by 1 year $15 \%$ to $30 \%$ have occluded. ${ }^{4}$ Arterial grafts behave differently; the cause of LITA occlusion or attenuation has been attributed to flow competition from the native coronary. ${ }^{5,6}$ In contrast, vein graft patency appears to correlate in a negative manner with the severity of the stenosis in the native artery. ${ }^{7}$

The OPCAB technique has generated some concern regarding the anastomosis of the LITA to the LAD, but advances in local myocardial stabilization techniques have improved angiographic graft patency rates. ${ }^{8}$ Off-pump arterial grafts to the circumflex and right coronaries have been noted to have lower early patency rates, ${ }^{1}$ but serial loss of the distal limb of composite arterial grafts has not previously been reported.

In the first 2 cases, there was a significant stenosis proximal to the distal graft insertion, but flow in the native vessel remained brisk. Furthermore, the RITA graft caliber at this point was considerably less than that of the native vessel ( $2 \mathrm{~mm}$ vs $4 \mathrm{~mm}$ ). We speculate that flow in the composite graft at this site was considerably less than in the native vessel. It is interesting that in the first case the graft to the left ventricular branch of the RCA remained patent. This branch was occluded proximally before the operation, so the graft had no flow competition from the native RCA.

The RCA lesion was well suited to angioplasty in the first 2 cases. An alternative revascularization strategy would therefore 
have been to perform OPCAB with a simple arterial composite graft combined with elective percutaneous intervention for the RCA. Integrated coronary revascularization with combined elective percutaneous intervention and minimally invasive direct coronary artery bypass (MIDCAB) has increasingly been reported, with encouraging results. ${ }^{9-11}$ The optimal approach remains a matter of contention, however, because it is unclear which step (percutaneous intervention or coronary artery bypass grafting) should be performed first. Some centers are performing same-day revascularization, and even single-procedure integrated coronary revascularization, with coronary artery bypass grafting taking place in the catheter laboratory. Randomized trials are needed to assess the benefits of these various approaches.

\section{Conclusion}

These cases highlight a potential limitation of composite arterial grafts that include a distal limb to an RCA with antegrade flow. The most distal limb is particularly susceptible to attenuation as a result of competitive flow in the native RCA. Such patients may be candidates for alternative grafting techniques to the RCA or for the combination of percutaneous intervention to the RCA with grafts to the left coronary vessels.

\section{References}

1. Omeroglu SN, Kirali K, Guler M, Toker ME, Ipek G, Isik O, et al. Midterm angiographic assessment of coronary artery bypass grafting without cardiopulmonary bypass. Ann Thorac Surg. 2000;70:844-9.
2. Calafiore AM, Teodori G, Di Giammarco G, Vitolla G, Maddestra N, Paloscia L, et al. Multiple arterial conduits without cardiopulmonary bypass: early angiographic results. Ann Thorac Surg. 1999;67:450-6.

3. Barra JA, Bezon E, Mansourati J, Rukbi I, Mondine P, Youssef Y. Reimplantation of the right internal thoracic artery as a free graft into the left in situ internal thoracic artery (Y procedure): one-year angiographic results. J Thorac Cardiovasc Surg. 1995;109:1042-8.

4. Bourassa MG. Long-term vein graft patency. Curr Opin Cardiol. 1994;9:685-91.

5. Siebenmann R, Egloff L, Hirzel H, Rothlin M, Studer M, Tartini R. The internal mammary artery 'string phenomenon': analysis of 10 cases. Eur J Cardiothorac Surg. 1993;7:235-8.

6. Shimizu T, Hirayama T, Suesada H, Ikeda K, Ito S, Ishimaru S. Effect of flow competition on internal thoracic artery graft: postoperative velocimetric and angiographic study. J Thorac Cardiovasc Surg. 2000;120:459-65.

7. Manninen HI, Jaakkola P, Suhonen M, Rehnberg S, Vuorenniemi R, Matsi PJ. Angiographic predictors of graft patency and disease progression after coronary artery bypass grafting with arterial and venous grafts. Ann Thorac Surg. 1998;66:1289-94.

8. Poirier NC, Carrier M, Lesperance J, Cote G, Pellerin M, Perrault LP, et al. Quantitative angiographic assessment of coronary anastomoses performed without cardiopulmonary bypass. J Thorac Cardiovasc Surg. 1999;117:292-7.

9. Wittwer T, Cremer J, Boonstra P, Grandjean J, Mariani M, Mugge A, et al. Myocardial "hybrid "revascularisation with minimally invasive direct coronary artery bypass grafting combined with coronary angioplasty: preliminary results of a multicentre study. Heart. 2000;83:58-63.

10. Riess FC, Schofer J, Kremer P, Riess AG, Bergmann H, Moshar S, et al. Beating heart operations including hybrid revascularization: initial experiences. Ann Thorac Surg. 1998;66:1076-81.

11. Cohen HA, Zenati M, Smith AJ, Lee JS, Chough S, Jafar Z et al. Feasibility of combined percutaneous transluminal angioplasty and minimally invasive direct coronary artery bypass in patients with multivessel coronary artery disease. Circulation. 1998;98:1048-50. 